\title{
Heart disease risk among metabolically healthy obese men and metabolically unhealthy lean men
}

\author{
Ian Janssen
}

§ See related article page 1301

$I^{0}$ $\mathrm{n}$ this issue of $C M A \mathcal{}$, St-Pierre and colleagues ${ }^{1}$ present the results of a longitudinal cohort study conducted in Quebec to determine the contribution of metabolic factors to cardiovascular disease. The authors found that among study participants, the risk of ischemic heart disease increased when components of insulin resistance syndrome, or the metabolic syndrome (MetS), were present. Specifically, they determined that although obese men were more likely to have the MetS, obese men without the MetS were not at increased risk of ischemic heart disease. Conversely, lean men with the MetS had an increased risk of ischemic heart disease.

The MetS represents a clustering of cardiovascular disease and diabetes risk factors that include high blood pressure, dyslipidemia and high blood glucose levels. The MetS has been given many names, including insulin resistance syndrome, ${ }^{2}$ syndrome $\mathrm{X}^{3}$ and the deadly quartet. ${ }^{4}$ Only recently has a general consensus been reached to use the term "metabolic syndrome," which has in part contributed to the development of an International Classification of Disease code (277.7) for this condition. Numerous risk factors and criteria have been used to diagnose the MetS (e.g., the criteria used by St-Pierre and colleagues ${ }^{1}$ ), and at present there are no globally accepted diagnosis criteria. The most commonly employed clinical criteria are based on the US National Cholesterol Education Program guidelines ${ }^{5}$ and include the presence of at least 3 of the following: high blood pressure ( $\geq 130 / 85 \mathrm{~mm} \mathrm{Hg}$ ), high triglyceride levels $(\geq 1.60 \mathrm{mmol} / \mathrm{L}$ ), low high-density lipoprotein cholesterol levels $(<1.04 \mathrm{mmol} / \mathrm{L})$, high fasting glucose levels $(\geq 6.1$ $\mathrm{mmol} / \mathrm{L}$ ) and central obesity (waist circumference $>102 \mathrm{~cm}$ in men and $>88 \mathrm{~cm}$ in women). Using these criteria, about $17 \%$ of Canadian men and $13 \%$ of Canadian women have the MetS. ${ }^{6}$

The MetS is a strong risk factor for type 2 diabetes (hazard ratio $[\mathrm{HR}] 3.51,95 \%$ confidence interval [CI] $2.47-4.98),{ }^{7}$ coronary artery disease (HR 2.96, 95\% CI $2.36-3.79)^{8}$ and premature mortality (HR 1.81, $95 \%$ 1.24-2.65). ${ }^{8}$ There are multiplicative effects between the components of the MetS and disease risk, such that the MetS predicts disease outcomes to a greater extent than the sum of the risk estimates of the individual MetS components. ${ }^{9}$ This speaks to the clinical importance of identifying high-risk patients with the MetS.

Obesity is one of the central components in the development of the MetS. The likelihood of having the MetS is increased by more than 5 -fold in overweight people and by more than 20-fold in obese people in comparison with people with a healthy body weight. ${ }^{10}$ Thus, from a population perspective, preventing and treating obesity would help reduce the incidence of the MetS. In both the clinical and research setting, adiposity status is typically classified according to the body mass index (BMI), which is determined by taking a person's weight and dividing it by the square of their height $\left(\mathrm{kg} / \mathrm{m}^{2}\right)$. Among adults, BMI values of $25-29.9 \mathrm{~kg} / \mathrm{m}^{2}$ indicate overweight, and BMI values of 30 $\mathrm{kg} / \mathrm{m}^{2}$ or more indicate obesity. ${ }^{11}$ Although there are more direct and accurate methods for classifying adiposity status than BMI, such as underwater weighing measures of body fat, these body composition measures are impractical for the clinical setting.

Despite the strong relation between adiposity level and the MetS, about $40 \%$ of the obese population does not have the MetS, ${ }^{10}$ a condition that has been termed "metabolically normal, obese." Conversely, about $6 \%$ of the normal-weight population has the MetS, ${ }^{10}$ a condition that has been termed "metabolically obese, normal weight." In their study, St-Pierre and colleagues ${ }^{1}$ determined that the risk of ischemic heart disease is increased among "metabolically obese, normal weight" people but not among "metabolically normal, obese" people.

These findings raise the question as to whether health care practitioners should prescribe weight loss to obese patients who do not have the MetS. The answer to this question is a resounding "yes." In addition to the MetS, obesity is a risk factor for numerous other health outcomes (e.g., arthritis, certain cancers, depression) ${ }^{11}$ and weight loss in obese people without the MetS will offer protection against these nonmetabolic diseases. Further, because the duration of overweight and obesity is associated with the presence of the MetS, ${ }^{12}$ weight loss in obese people without the MetS may offer some protection against the development of this condition.

The findings of St-Pierre and colleagues ${ }^{1}$ also raise the question as to what treatments should be prescribed for normal-weight patients with the MetS. Pharmacologic treatment of the individual components of the MetS will be the preferred approach of many clinicians and patients. ${ }^{13}$ 
Lifestyle changes should, however, be given an equal if not greater emphasis. Expert committees recommend that normal-weight patients (as well as overweight and obese patients) with the MetS should improve their physical activity and dietary habits. ${ }^{5,14} \mathrm{~A}$ recent study found that $31 \%$ of patients with the MetS were no longer classified as having the syndrome after participating in a 20-week aerobic exercise program. ${ }^{15}$ Furthermore, a high physical fitness level greatly attenuates the increased cardiovascular disease risk among normal-weight (as well as overweight and obese) people with the MetS. ${ }^{16}$ Regarding diet, there is great debate as to the optimal proportions of carbohydrates, protein and fat to treat the MetS. ${ }^{17}$ Physicians and dieticians may therefore want to focus on each patient's specific metabolic alterations ${ }^{18}$ such as reducing salt intake in patients with high blood pressure.

In summary, the MetS is a highly prevalent condition that is associated with an increased morbidity and mortality risk. Obesity is a risk factor for the MetS; however, patients with the MetS have an increased risk of ischemic heart disease regardless of their adiposity status. The MetS in all patients should be aggressively treated.

Ian Janssen is an assistant professor at the School of Physical and Health Education, and Department of Community Health and Epidemiology, Queen's University, Kingston, Ont.

Competing interests: None declared.

\section{References}

1. St-Pierre AC, Cantin B, Mauriège P, Bergeron J, Dagenais GR, Després JP, et al. Insulin resistance syndrome, body mass index and the risk of ischemic heart disease. CMA7 2005;172(10):1301-5.

2. DeFronzo RA, Ferrannini E. Insulin resistance. A multifaceted syndrome responsible for NIDDM, obesity, hypertension, dyslipidemia, and atherosclerotic cardiovascular disease. Diabetes Care 1991;14:173-94.

3. Reaven GM. Banting Lecture 1988. Role of insulin resistance in human disease. Diabetes 1988;37:1595-607.

4. Kaplan NM. The deadly quartet. Upper-body obesity, glucose intolerance, hypertriglyceridemia, and hypertension. Arch Intern Med 1989;149:1514-20.

5. Expert Panel on Detection Evaluation and Treatment of High Blood Cholesterol in Adults. Executive summary of the third report of the National Cholesterol Education Program (NCEP) Expert Panel on Detection Evaluation and Treatment of High Blood Cholesterol in Adults (Adult Treatment Panel III). $7 A M A$ 2001;285:2486-97.

6. Ardern CI, Katzmarzyk PT, Janssen I, Ross R. Discrimination of health risk by combined body mass index and waist circumference. Obes Res 2003;11:135-42.

7. Sattar N, Gaw A, Scherbakova O, Ford I, O'Reilly DS, Haffner SM, et al. Metabolic syndrome with and without C-reactive protein as a predictor of coronary heart disease and diabetes in the West of Scotland Coronary Prevention Study. Circulation 2003;108:414-9.

8. Isomaa B, Almgren P, Tuomi T, Forsen B, Lahti K, Nissen M, et al. Cardiovascular morbidity and mortality associated with the metabolic syndrome. $\mathrm{Di}$ abetes Care 2001;24:683-9.

9. Golden SH, Folsom AR, Coresh J, Sharrett AR, Szklo M, Brancati F. Risk factor groupings related to insulin resistance and their synergistic effects on subclinical atherosclerosis: the atherosclerosis risk in communities study. Diabetes 2002;51:3069-76.

10. Park YW, Zhu S, Palaniappan L, Heshka S, Carnethon MR, Heymsfield SB. The metabolic syndrome: prevalence and associated risk factor findings in the US population from the Third National Health and Nutrition Examination Survey, 1988-1994. Arch Intern Med 2003;163:427-36.

11. World Health Organization. Obesity: Preventing and managing the global epidemic. Report of a WHO consultation on obesity. Geneva: The Organization; 1998.

12. Janssen I, Katzmarzyk PT, Ross R. Duration of overweight and metabolic health risk in American men and women. Ann Epidemiol 2004;14:585-91.

13. Ginsberg HN. Treatment for patients with the metabolic syndrome. Am 7 Cardiol 2003;91:29E-39E.

14. Pearson TA, Blair SN, Daniels SR, Eckel RH, Fair JM, Fortmann SP, et al. AHA guidelines for primary prevention of cardiovascular disease and stroke: 2002 update: consensus panel guide to comprehensive risk reduction for adult patients without coronary or other atherosclerotic vascular diseases. American Heart Association Science Advisory and Coordinating Committee. Circulation 2002;106:388-91.

15. Katzmarzyk PT, Leon AS, Wilmore JH, Skinner JS, Rao DC, Rankinen T, et al. Targeting the metabolic syndrome with exercise: evidence from the HERITAGE Family Study. Med Sci Sports Exerc 2003;35:1703-9.

16. Katzmarzyk PT, Church TS, Janssen I, Ross R, Blair SN. Metabolic syndrome, obesity, and mortality: impact of cardiorespiratory fitness. Diabetes Care 2005;28:391-7.

17. Grundy SM, Abate N, Chandalia M. Diet composition and the metabolic syndrome: what is the optimal fat intake? Am 7 Med 2002;113(Suppl 9B):25S-29S.

18. Szapary PO, Hark LA, Burke FM. The metabolic syndrome: a new focus for lifestyle modification. Patient Care 2002;36:75-88.

Correspondence to: Dr. Ian Janssen, School of Physical and Health Education, Department of Community Health and Epidemiology, Queen's University, Kingston ON K7L 3N6; janssen@post.queensu.ca

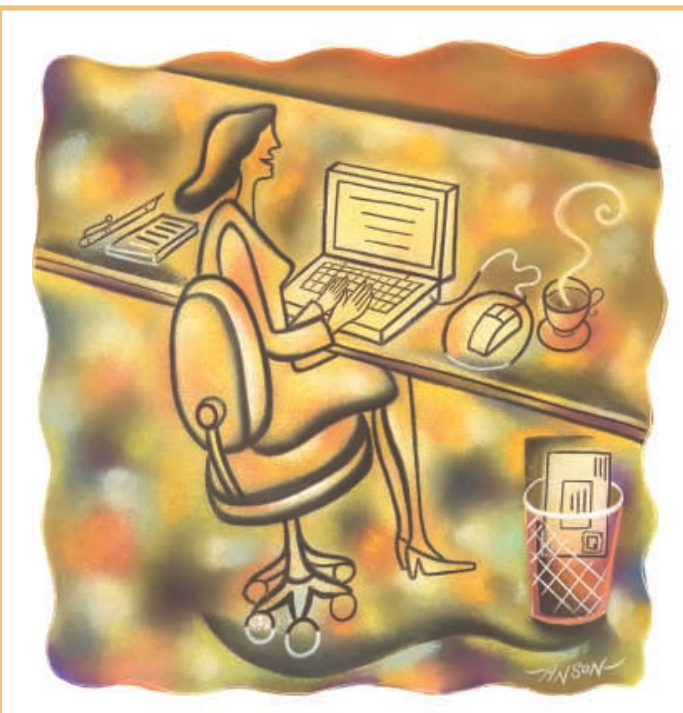

\title{
Online manuscript submissions and peer review
}

\author{
NOW AVAILABLE AT CMAJ \\ http://mc.manuscriptcentral.com/cmaj
}

